\title{
Design Office Control using Information Technology (DOCIT)
}

\author{
D.J.Hodgins; European Technology for Business Ltd \\ Greenways House, 2 Marford Road, \\ Wheathampstead, Hertfordshire, \\ United Kingdom \\ ALA 8AS \\ Telephone: 00441582629310 \\ Fax: $\quad 00441582629311$ \\ Email:_denis.hodgins@etb.co.uk
}

\begin{abstract}
This project offers a new approach to looking at how information is used and controlled within an organisation. The findings will be applicable to both design and manufacturing, and manufacture to print businesses. The only solutions currently available to SMEs are high value products that constrain the user to a particular software solution. With ever increasing usage of open databases more bespoke applications can be written which can be changed to suite a particular business. This paper discusses the process that the six SMEs within the DOCIT programme undertook to achieve effective control of their design and manufacturing information. The methods employed are explained along with some of the innovative findings, and the solutions discussed in detail. The DOCIT processes have shown that controlling this information will reduce wastage within the companies to between $5 \%$ and $10 \%$ of their turnover.
\end{abstract}

Keywords

Information flow, Business Process, Part Number, Change control, Product data control. 


\section{BACKGROUND}

The Design Office Control using Information Technology (DOCIT) is an Esprit 8.20 project which concentrates on improving one key internal business process within the Supply Chain structure, by introducing a suitable IT system into manufacturing SMEs. The specific area to be addressed is the control of all manufacturing data including drawings and the associated bill of materials plus configuration control. The aim is that information generated in the design area, and used by many departments including manufacturing, purchasing, quality and sales, will be controlled. Hence, once the procedures and IT solution are put in to place, each SME will be functioning more efficiently.

The efficiency of each business process affects the overall performance of any company. Hence, significant savings can be made if key internal business processes are well defined and controlled. This has led to the development of many different IT software packages, for example Manufacture Resource Planning (MRP), Product Data Management, and Sales Order Enquiries. For manufacturing companies one of the key causes of scrap and waste can be directly attributed to the poor control of manufacturing data. Large companies and SMEs are therefore now looking at introducing IT in to their business to control design office data. The six manufacturing SMEs involved in this project believe that their waste, which is between $5 \%$ and $10 \%$ of their turnover, can be significantly reduced by the correct use of procedures and IT in this area. Therefore they wish to concentrate on developing a suitable IT system for this one specific application.

\section{APPROACH}

At the start of the project it became apparent that the understanding of design and manufacturing information in terms of what it was, and where it was used was different in each company. Thus, at the beginning of the project, training in the understanding of how a business could use design information was given. This also encompassed training in the various elements associated with manufacturing information, i.e. part numbers, bill of materials etc. This gave all the SMEs involved within the project an equal understanding of the interactions of design with other departments within a business, and the type and structure of information that could be controlled.

For the companies to fully understand at a detail level how design and manufacturing information was used, an information process map was used. Because these companies where small, this was carried out using a simple input, output analysis. Once this had been achieved each of the companies had a process system map, which defined where information was flowing within the business. This information flow was then analysed for duplication and gaps. The process map was then changed to improve the accuracy of information flow. During this phase the possible savings were analysed. It was at this point that the first major 
decision was made by the consortium members. If the return on investment figures (ROI) where not good, then no further action would have been taken. The resulting ROI from the consortium members was indicating an ROI of 1.4 years, which was considered by all of the consortium to be good.

Each of the SMEs then analysed their current paper and digital systems to define how these would have to change. Any solution would have to consider the infrastructure already in place unless it was discovered to be the main source of errors, in which case it would be removed or replaced.

All of the SMEs now have solutions in which they are currently implementing. Some of the SMEs are so convinced that the control of this data will resolve a number of issues that they have immediately gone for a full implementation throughout the business.

\section{SME TRAINING}

The SMEs were trained in the understanding of the interactions of the following typical business functions.

\subsection{The Role of Design \& Engineering in Business Strategy}

The business and financial success of most manufacturing organisations depends on their ability to identify the needs of customers and to quickly create products that fulfil these needs with regard or both cost and quality. Achieving these goals is not solely a marketing, design or manufacturing function; instead, it is a crossfunctional, boundary spanning process that permeates the interfaces between these functions (see Figure 1).

The marketing function mediates the interactions between the firm and its customers. Typically, marketing personnel identify product opportunities, define market segments and examine customer needs. In addition, marketing is responsible for product launches, pricing negotiations, promotion and product launches.

The design $\&$ engineering function focuses on defining the physical form of the product to best meet customer requirements. It is responsible for both engineering design (the development of a product from its technical conception through detail design, and the design of the related manufacturing process and tooling) and industrial design (the aesthetics, styling and user-interface dimension).

The manufacturing function is responsible for designing and operating the production system in order to manufacture the firm's product lines. This involves management choices with regard to production technology, process management, quality, logistics and capacity planning. 


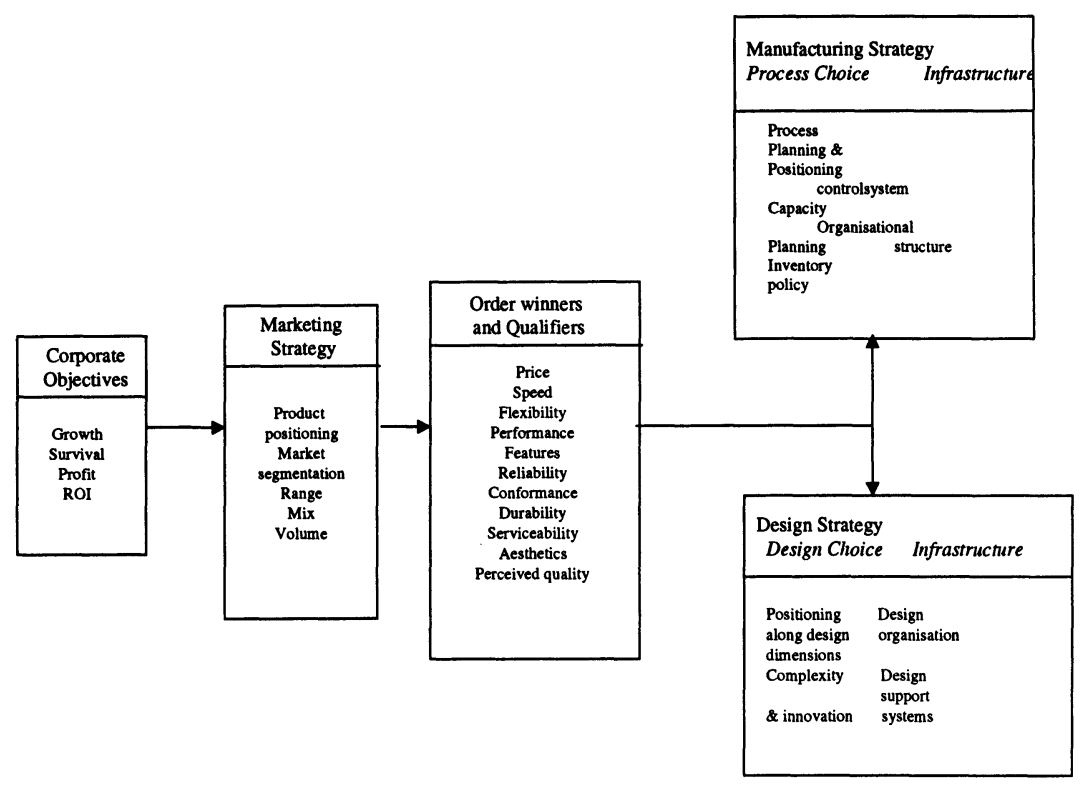

Figure 1 Design engineering in business strategy (Fitzsimons et al, 1991).

Developing new products can have a significant impact on the relationships between these functional areas as decisions taken in one area can cause adverse reactions elsewhere. Examples of this type of behaviour would include marketing promising delivery with unrealistic delivery dates, design \& engineering developing unmanufacturable products and manufacturing failing to produce a quality product.

\subsection{Managing Business Process Interfaces}

Organisations have become increasingly concerned about stimulating and facilitating communication between the various functional areas. This trend is particularly evident in the area of new product development because of its crossfunctional nature. Simultaneous engineering, quality function deployment and cross-functional project teams are among the most widely used practices in this area. Furthermore, this type of internal network of functional interfaces is frequently extended to include an external network of customers and suppliers where closer collaboration in new product development decisions can be critical. Figure 2 illustrates the nature of these internal and external networks. 


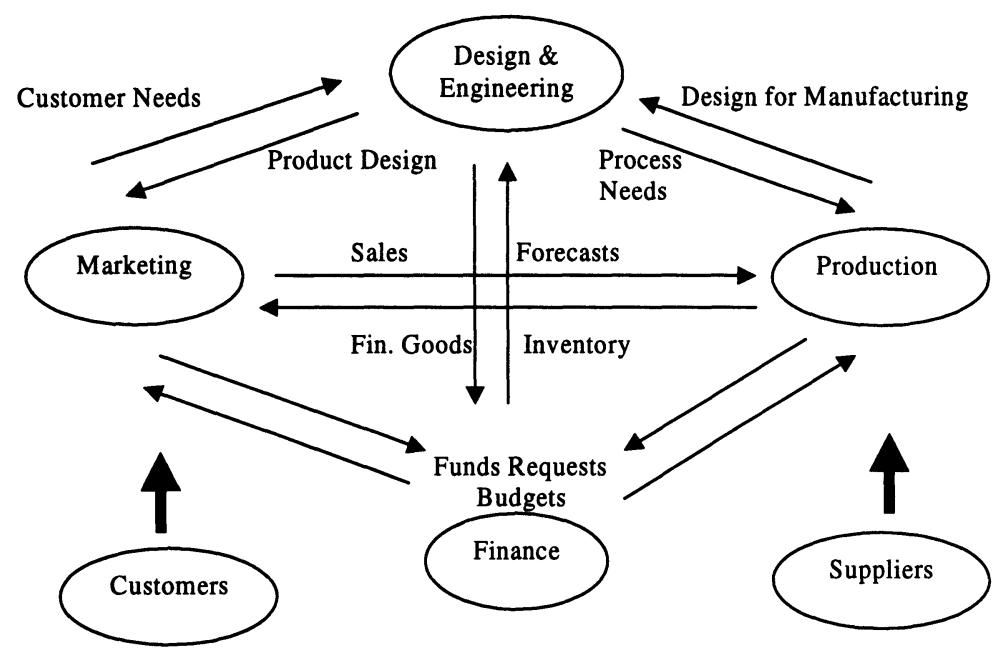

Figure 2 Internal and external networks (adapted from Song et al, 1997).

As Figure 2 suggests, there is considerable interchange of information on factors influencing new product development. How this exchange of inputs and outputs is processed will have a considerable impact on the success or failure of new product development.

Any analysis of how these interfaces are managed needs to address the role of marketing \& engineering within the organisation. This role may be either negligible or substantial. In the former case, product design and specification will typically be provided by the customer (as in basic sub-contract manufacture), whilst in the latter case the design will typically be developed in-house (companies who design, manufacture and market their own products). Alternatively, some companies carry out both sub-contract and own-product functions. How to manage the above interfaces will be dependent on the strategic role of design \& engineering within the organisation. 


\section{DOCIT PROJECT SOLUTIONS}

These were applied to the following types of companies:design and manufacture manufacture to print

The DOCIT project during its life has realised the following features that have attributed to its success. These are as follows;

The solutions to have the most impact and least disruption should be of a bespoke nature which fits into the SME current working practices. It also must allow for future growth.

Before any major changes to the business are undertaken, a business or information flow mapping should be carried out. This will give the business a thorough understanding of how it operates with its existing manual and electronic information and business flows.

A specification of the required solution can then be generated. This specification will allow the business to fully understand what they require. When they start to consider suitable solution providers, they will be able to understand if the software solution will fit into their business. If it does not, then changes can be made. This approach ensures that the IT solution is not driving the business.

Once a suitable solution provider has been found, an implementation plan can be derived. This plan will not only cost the bought out items, i.e. hardware and software, it will also detail the resource efforts required by the company to achieve the full integration of the solution. From this, a return on investment figure can be ascertained. The business can then make an informed decision whether they want to proceed. This will ensure that the solution has the full backing of the company, an unforeseen surprises will be kept to a minimum.

\subsection{Information Flow Mapping}

The project has identified a number of key technological business issues. The consortium of SMEs have all analysed their business process in relation to the flow of design information and the impact that it has on the rest of the business. This exercise proved to be most valuable. None of the SMEs in the consortium had considered mapping out the information flow for this type of data, whether it was electronic or manual.

Before the 'business process mapping' was carried out, other projects under the Esprit programme where visited to determine if these projects could be used. It was decided that the best approach for the SMEs was for them to undertake the business mapping themselves but being guided by the project and best practice co- 
ordinators. The SMEs involved are all quite small, averaging 60 people, therefore it was felt that applying a simple input- process-output technique would be sufficient. Each business started from the design/manufacturing areas and gathered together all of the data (whether it was paper based or electronic) from each of the departmental employees and mapped out the following; who delivered the information, what was done with it, who was it passed to. This approach enabled the business to determine the added value that was being done by the operation. It also highlighted gaps in the information and also duplication of work within the department.

The next phase then looked at the flow of information outside of the design and manufacturing areas. This highlighted a number of key business issues. The companies truly discovered the extensive usage of this data. Prior to this, the business understood that the data was used throughout the company, but seeing it mapped out actually brought home the complexities of how the business was being run. The goal now was to understand the inefficiencies of the process. This was achieved by applying time and waste figures that could be attributable to the process. This also considered duplication and gaps across the business functional boundaries.

\subsection{Part Numbering}

Figure 3 shows the extent that a single part number within a business is actually used. This example is for a sheet metal company. It would obviously be more complex for businesses in the electronics sector. The accuracy of this data has a direct impact on the profitability of these companies. As a result these companies have now realised that this data is key information in most of their internal functional departments.

It was also found that the majority of MRP packages affordable to SMEs operate using only one part number, although some would allow the use of suppliers part numbers within the in built purchasing module. The problems that 'make to print' companies have is how to control the plethora of part numbers that can exist for a particular part. An example of this is shown in Table 1. It is easy to understand that a business dealing with a large customer base will have significant problems in controlling this information. 


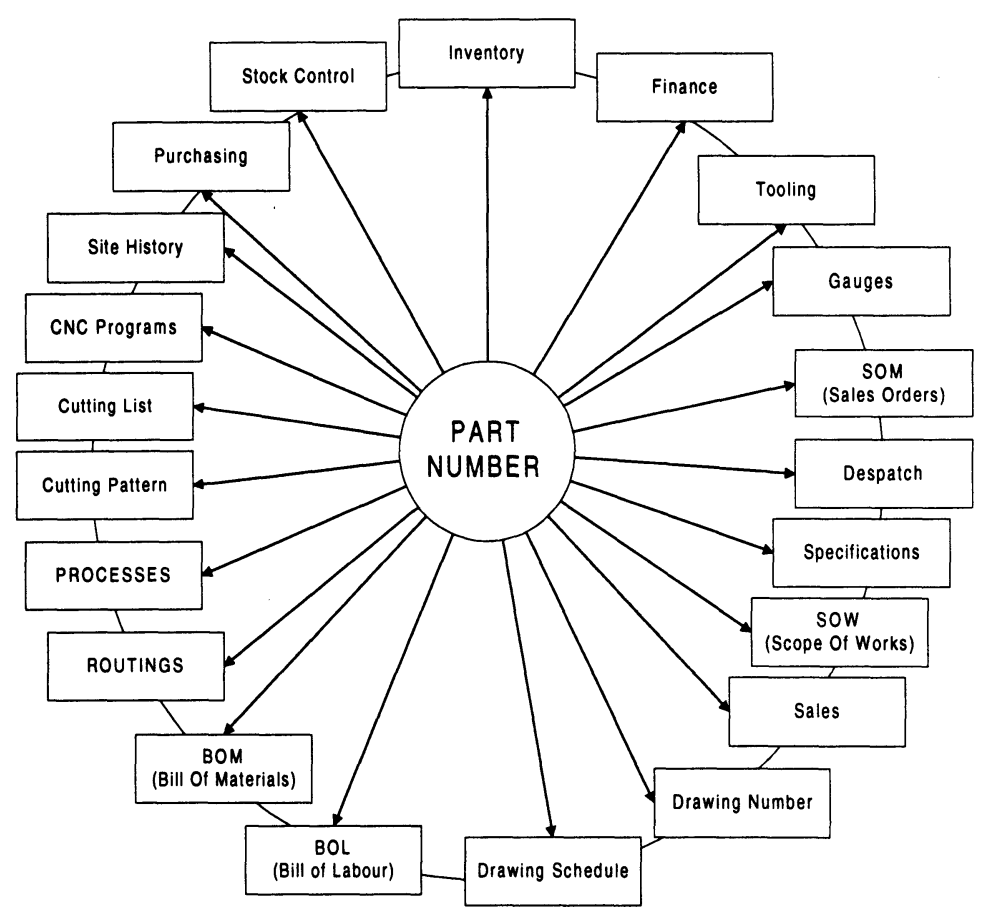

Figure 3 Part number usage within a sheet metal business.

Table 1 Part numbers and their proliferation.

\begin{tabular}{|l|l|l|l|l|l|}
\hline $\begin{array}{l}\text { PEC } \\
\text { Co } \\
\text { No }\end{array}$ & $\begin{array}{l}\text { CUSTOME } \\
\text { R No }\end{array}$ & $\begin{array}{l}\text { MANUFACTURER } \\
\text { No }\end{array}$ & $\begin{array}{l}\text { SUPPLIER } \\
\text { ORDER } \\
\text { CODE }\end{array}$ & $\begin{array}{l}\text { MF } \\
\text { TR }\end{array}$ & DESCRIPTION \\
\hline $\begin{array}{l}\text { E123 } \\
456\end{array}$ & $\begin{array}{l}\text { KLM25364 } \\
1\end{array}$ & AM27C512-120PC & $563-018$ & $\begin{array}{l}\text { AM } \\
\text { D }\end{array}$ & $\begin{array}{l}\text { 512K (64K*8) CMOS } \\
\text { OTP PROM 120ns } \\
\text { ACCESS, 12.75V VPP }\end{array}$ \\
\hline $\begin{array}{l}\text { E123 } \\
456\end{array}$ & $\begin{array}{l}568972154 \\
6-123\end{array}$ & CY27C512-120PC & $633-458$ & $\begin{array}{l}\text { CY } \\
\text { P }\end{array}$ & $\begin{array}{l}\text { 512K (64K*8) CMOS } \\
\text { OTP PROM 120ns } \\
\text { ACCESS, 12.75V VPP }\end{array}$ \\
\hline $\begin{array}{l}\text { E123 } \\
456\end{array}$ & 987654321 & M27C512-12B1 & $594-398$ & ST & $\begin{array}{l}\text { 512K (64K*8) CMOS } \\
\text { OTP PROM 120ns } \\
\text { ACCESS, 12.75V VPP }\end{array}$ \\
\hline $\begin{array}{l}\text { E123 } \\
456\end{array}$ & TY-5897PL & NM27C512N120 & $527-890$ & $\begin{array}{l}\text { NS } \\
\text { C }\end{array}$ & $\begin{array}{l}\text { 512K (64K*8) CMOS } \\
\text { OTP PROM 120ns } \\
\text { ACCESS, 12.75V VPP }\end{array}$ \\
\hline
\end{tabular}

The solution is a database system that automatically allocates part numbers. The database controls the co-ordination of this part number so it can reference suppliers 
and customers own part numbers. The companies part number will then contain references to the following;

$\checkmark$ customer part number (various depending on the number of customers)

$\checkmark$ suppliers number (various)

$\checkmark$ manufacturers number (various)

$\checkmark$ country of origin (various)

This information is controlled and can be fed in batch mode or real time to MRP packages or shop floor infinite scheduling programmes. This enables the MRP package to only have to consider one part number, and more importantly the complete operation of the business is achieved using one part number for all of the internal processes.

The inputting of customers parts lists can be electronic, or scanned if paper format is supplied. It has been found that companies operating good supply chain principles have not found it an issue to have the parts lists sent to them electronically, since both see the benefit this achieves in terms of eliminating errors in re-keying the data. A search algorithm is used which is based on a descriptor type field to determine if the component is already in use. If it is, then the companies part number is used, if not, then a new part number is allocated to the component. The user is then requested for the purchasing details. Any descriptions the system cannot fully understand are then highlighted for manual selection. Further enhancements to the system can be an artificial intelligence that can learn a particular customers method of describing their components.

The completed part list is then fed into the MRP package. This can also be a manufacturing BOM or scheduling package etc. This IT solution allows the 'make to print' companies to reduce inventory levels, gain economies of scale purchasing power, apply leaner just in time, and reduce storage space within the factory. The production engineering areas have reduced workload due to a reduced number of active part numbers within the business.

\subsection{Change Control}

Another area highlighted during the analysis phase is the control of the changing engineering data. Each of the SMEs have looked at this area, and again, the solutions proposed appear to be simple in process form, but the IT solution to cater for all the elements of data control are not available within any software vendors other than high end enterprise packages. These are costly to purchase and maintain, and require high-end computer hardware solutions. SMEs could not afford to justify the level of expenditure required.

It was interesting to find out that even with the new manufacturing information systems and product data management systems available, it is still difficult to determine how much a change to a product is going to cost. If a modification was 
required on a panel electronic circuit board that required changing the value of a component on the board, what would be the true cost incurred by the company.

The type of information that needs to be considered is as follows;

$\checkmark \quad$ Point of embodiment needs to be determined plus costs of possible scrap of components already in stores.

$\checkmark$ Disruption costs to the company need to be understood.

$\checkmark$ Determine what information needs to be changed.

$\checkmark$ Drawings

$\checkmark$ Parts list

$\checkmark$ Gerber files

$\checkmark$ Pick and place programme (there could be a number of these)

$\checkmark$ Surface mount cartridges (SMT)

$\checkmark$ SMT programmes

$\checkmark \quad$ In circuit test (ICT) programme

$\checkmark \quad$ ICT test fixture

$\checkmark$ Functional test programme

$\checkmark$ Functional test fixture

$\checkmark$ Functional Test specifications

$\checkmark$ Conformal coating program

$\checkmark$ Repair information

$\checkmark$ Technical publications

$\checkmark$ Et al

There is a lot of information that needs to be changed just for what could be $0.1 \mathrm{ECU}$ worth of components. It is the understanding of this information, and its true costs that need to be determined. This production information for a small company tends to be in the heads of the production staff. A complete list is not readily available from the current systems. Once these costs are fully understood, possible changes (on what first appears to be a good idea) can lead a company into cost overruns.

It is normally the front end of the business (sales, marketing etc) that do not fully understand the cost of change. For a large mechanical assembly the costs of change could be quite high. For instance, a petrol station price sign can easily be changed in length, but if the width would to change over $90 \%$ of the manufacturing drawings would have to alter, plus material sizes where no longer standard. This 'simple' change has led one company to loose significant money, not just from the cost of the change, but due to the impact it has on design and manufacturing departments in changing the information. This information tends to be late and as a consequence the shop floor has to squeeze the job in, resulting in overtime payments, and missed deliveries which may incur fixed penalties. Customer satisfaction levels are also reduced. 
What is required is an easier interface between what is best described as the design bill of material and the production bill of material. Thus if there is to be a change to the design bill of material, all the other items and functional departments (design, manufacturing, purchasing, accounts etc) that are affected can be quickly analysed to determine the true cost of the change.

\subsection{Intranet Solution}

One other solution that two companies are investigating is the use of Intranet technology within the business to control the design and engineering data. The reasoning behind this approach to design a system that can feed new or changed information during the product development phases to the relevant users of the information. This system uses intranet technology to control the life cycle of new product designs. The system allows discrete departments to hold their own data, but data access by other departments is simple using hyper link searches built in to the design process. This also means the original application that the data was created in is irrelevant. The business process is also embedded within the documents. This allows users to quickly make requests concerning the data. The intranet solution is structured in terms of traditional functional boundaries. The particular functions/departments requirements are stored within this area. Links are built in to the data which guides users to data that impacts on other departments. If changes are required then discussion groups can be easily formed, testing out reaction to the specification change request. The project leader can then make the necessary changes knowing that all the relevant areas have been considered, and they will also be up to date.

The creation of the hyper link structures is proving to be at the heart of the system. When a particular item or piece of information has changed, an automatic Email is sent to the relevant employees who would have to act on the changed information. This link with Email is proving to be extremely efficient. Information is being given to people, whereas people only discovered changes after they had been done. This would cause waste due to the fact that the design process had continued with out the knowledge of the change. It is at the early stages of the product life cycle where information can be changing at a rapid pace. This system ensures that the people in the new product teams are kept up to date with this information.

The advantages of using this type of technology is that generally with each operating system supplied there is a web browser. Therefore it is a cheap solution for business to share information using this technology. The future phase of this project are to take the process one step further and introduce an extranet to some of the suppliers. When a company operates good supply chain methods, then it is just as important for the suppliers to be kept up to date with information changes. 


\section{SUMMARY}

It has been shown that within the design and manufacturing sector, SMEs face a challenging task to bring control into their design and manufacturing information and process flows. Most SMEs will already have some IT systems and business processes in place. To control the design and manufacturing information, these existing systems must be considered in the new process and information system design. It is most important that the SMEs thoroughly understand how the use of the information within the business is used by each of its personnel. Once this is understood a process map can be created which will describe their current status. An analysis can then be undertaken to improve the business process and information flows. When his has been done, the SME will have a thorough understanding of their business. The result of the analysis will then act as a cardinal points specification to review possible solution providers, so to ensure what they are 'selling' will actually fit into the business.

Thus from the specification suitable solution providers can be approached. This will ensure that any solution proposed will fit into the business processes and information flows. The SMEs will also be confident in interrogating any possible solution provider to ensure that any solution being proposed will actually suit the business, and if it does not what could be changed to make it fit. The implementation plan will then ensure that the company is aware of the return on investment and the amount of effort required to ensure a trouble free implementation. It is during this stage that most implementations fail. The DOCIT process has ensured that the methods described for manufacturing SMEs ensure that controlling the design and manufacturing data will impact on the companies turnover by saving between $5 \%$ to $10 \%$ of this value.

\section{REFERENCES}

Fitzsimons, J. A., Kouvelis, P., Mallick, D. N. (1991) 'Design Strategy and its Interface with Manufacturing and Marketing: A Conceptual Framework', Journal of Operations Management, Vol. 10, No. 3, pp. 398-415.

Song, X. M., Montoya-Weiss, M. M. and Schmidt, J. B. (1997) 'Antecedents and Consequences of Cross-Functional Co-operation: A Comparison of R\&D, Manufacturing, and Marketing Perspectives', Journal of Product Innovation Management, Vol. 14, pp.35-47.

\section{BIOGRAPHY}

The author has worked in both large aerospace companies and small to medium enterprises. He has gained considerable experience in managing the engineering design processes of projects ranging from short term to major multi country aerospace design projects. Recently he has been running the Esprit project DOCIT. He is currently the Operations Director of European Technology for Business Ltd. The author currently specialises in business processes re-alignment 
using Information Technology as the final tool. This work is undertaken for SMEs within the United Kingdom.

Acknowledgements

Assistance in developing the best practice was given from the best practice coordinator Brian Fynes from the University College Dublin. He has spent many years developing best practice business processes for companies involved in manufacturing with emphasis on SMEs. His contributions have helped in the success of this project.

The following companies who all took active parts within the DOCIT project.

ASMEC Electronics Ltd

Dutton Engineering (Woodside) Ltd

Hocking NDT Ltd

Prosser Scientific Ltd

Sandland Manufacturing Services Ltd 